\title{
TABUADA DE MULTIPLICAÇÃO, UM DUELO PARA APRENDER MATEMÁTICA
}

Milena Luvison ${ }^{1}$

Alessio Gava

RESUMO: O presente trabalho apresenta o resultado de uma oficina envolvendo um aplicativo de celular, desenvolvida por três bolsistas do Projeto de Matemática do PIBID da Universidade Estadual do Paraná - campus Apucarana e realizada com quatro turmas do $6^{\circ}$ ano do Colégio Estadual Antônio dos Três Reis de Oliveira, da cidade de Apucarana. O objetivo da atividade foi trazer a tecnologia para dentro da sala de aula, mostrando para os estudantes como eles podem utilizar seus smartphones para a compreensão de uma determinada matéria. A proposta principal foi a de que os alunos aprendessem a tabuada de multiplicação, estudando de uma forma mais divertida e dinâmica, em vista de uma prova que teriam que realizar na semana seguinte. Considerações sobre a importância tanto do lúdico, quanto das novas tecnologias em sala de aula também serão tecidas. Por que, em nossas universidades, na formação de educadores/professores, não existem disciplinas centradas no lúdico?

Palavras-Chave: Duelo; Novas Tecnologias; Lúdico; Tabuada.

\section{Introdução}

Constitui fato estabelecido há bastante tempo a consciência de que a aprendizagem não é um processo passivo, no qual o discente desempenharia papel de mero receptor de informações e conceitos, como se fosse um 'recipiente a ser preenchido' de ideias, noções, teorias, etc. Com efeito, assim como na percepção não existe real passividade, pois ela acontece quando o sujeito é desperto e ativo, do mesmo modo, nos processos relacionados ao ensino-aprendizagem, todos os agentes envolvidos na verdade são atuantes, tanto os docentes, quanto os discentes; até nas chamadas 'aulas frontais' - nas quais, segundo uma imagem estereotipada, mas popular, o professor fala e o aluno limita-se a escutar. Pois se esse segundo não for desperto e ativo, a aprendizagem não ocorre; ou ocorre de modo imperfeito, com uma assimilação apenas parcial e superficial dos conceitos transmitidos pelo docente. Ora, uma vez que existe um pensamento consolidado acerca da subsistência de uma relação direta, nesse processo, entre o ser atuante e a aquisição de conhecimento, é mister, por parte do professor, pelo seu papel de mediador/facilitador de conhecimento, manter o aluno o quanto mais desperto, concentrado e ativo possível.

\footnotetext{
${ }^{1}$ Graduanda e bolsista PIBID do curso de Licenciatura em Matemática, Universidade Estadual do Paraná Campus Apucarana.Email: milena.luvison@hotmail.com

${ }^{2}$ Docente do curso de Licenciatura em Matemática, Universidade Estadual do Paraná - Campus Apucarana. Email: alessiogava@yahoo.it
} 
A bem de verdade, os docentes de Matemática já sabem 'desde sempre' que, sem atividades 'práticas', as regras e os teoremas são rapidamente esquecidos. Por isso, muitas vezes, eles exigem dos alunos em sala de aula, a resolução de listas de exercícios e de problemas, o que representa uma clássica - e, por que não dizer, geralmente eficaz atividade de 'fixação de conteúdos', na qual, evidentemente, o aluno tem que ser ativo. Mas, certamente, essa não é a única estratégia didática, e sem dúvida, aos olhos dos discentes, é a mais cansativa. Quando se trabalha com crianças ou pré-adolescentes, adotar outras estratégias para cativar a atenção desses e fazê-los trabalhar de modo ativo pode ser ainda mais eficaz e produtivo do que apenas 'mandá-los resolver exercícios'.

A nosso ver, o uso de jogos constitui alternativa muito válida até para a aquisição e a fixação de regras e noções matemáticas, particularmente com alunos ainda em tenra idade ou que estão entrando na fase da adolescência. Por isso, tanto o Referencial Curricular Nacional para a Educação Infantil (cf. CORRÊA; BENTO, 2014), quanto os Parâmetros Curriculares Nacionais de Matemática incentivam o uso de jogos em sala de aula, particularmente aqueles que possuem regras. Ademais, os Parâmetros "ressaltam também a importância do uso de novas tecnologias no processo de ensino e aprendizagem" (JACOBSEN; SPEROTTO, 2013, p. 3).

Todavia, mesmo estando no século XXI, é difícil ver aceito o uso das tecnologias em sala de aula. Muitos professores proibem o uso de smartphones, por exemplo, durante o período escolar. Aliás, isso frequentemente faz parte até das normas das instituições de ensino. Perguntamos: Por que não permitir que os alunos usem seus celulares em sala de aula para fazer pesquisas, tirar dúvidas e fazer anotações?

Nossa opinião é que o universo da tecnologia deve ser explorado e que o professor deve aprender a utilizá-la durante suas aulas. Os alunos de hoje em dia, com efeito, podem ser considerados 'nativos digitais' - para usar uma locução que se tornou popular - e usar a linguagem deles constitui evidentemente o melhor modo de comunicar e relacionar-se, o que permite ao docente assumir deveras seu papel de mediador e gerenciador do processo ensino-aprendizagem.

É importante despertar o interesse dos alunos em utilizar as tecnologias a favor do conhecimento, mostrando para eles que não é preciso estar sentado numa cadeira com o livro na mão para estar estudando e que até em seu momento de lazer eles podem, por exemplo, usar um aplicativo de celular para obter um conhecimento novo.

$\mathrm{Na}$ área da Matemática existem diversos jogos que podem ser empregados para melhorar o desempenho dos discentes nessa matéria, 'brincar' em sala de aula e despertar o interesse pelo conteúdo que está sendo ministrado. Quando o discente é convidado a jogar, ao invés que pegar seu caderno e resolver uma conta, seu interesse por aquela matéria aumenta. $O$ jogo prende a atenção do aluno, mesmo que esse tenha dificuldades com aquele determinado tópico. 
- Revista de Iniciação à Docência, v. 2, n. 2, 2017 Publicação: março, 2018 - ISSN 2525-4332

O jogo "Tabuadas de Multiplicação", desenvolvido pelo empresário argentino Pablo Goldstoff, é um exemplo de como a tecnologia pode ser levada de forma divertida, útil e produtiva para as salas de aula. Trata-se de um jogo que pode ser realizado de seis maneiras diferentes e uma dessas foi utilizada para realizar uma oficina no âmbito do Programa Institucional de Bolsas de Iniciação à Docência (PIBID) da Universidade Estadual do Paraná (UNESPAR - campus Apucarana), em agosto de 2017, no colégio Antonio dos Três Reis de Oliveira, no município de Apucarana.

O presente trabalho tem como objetivo apresentar um relato de tal oficina e, a partir dessa experiência, tecer algumas considerações sobre o uso de jogos eletrônicos em salas de aula, particularmente como ferramenta para o ensino de Matemática.

\section{A atividade}

Em 22 de agosto de 2017, três bolsistas do PIBID da Universidade Estadual do Paraná, graduandos em Matemática, propuseram uma atividade diferente para quatro turmas do $6^{\circ}$ ano do Colégio Estadual Antônio dos Três Reis de Oliveira, no município de Apucarana/PR. Atendendo a um pedido da professora orientadora do PIBID junto ao Colégio, feito naquele mesmo dia, tal atividade envolveu a aplicação da tabuada de multiplicação. Na semana seguinte, com efeito, haveria uma prova envolvendo tabuada e, segundo a professora, os alunos estavam apresentando muitas dificuldades para a compreensão do referido assunto. Após uma reunião online, os bolsistas decidiram então utilizar, na prática daquela tarde, o jogo Tabuada de Multiplicação. Tal jogo é um aplicativo para telefone celular, portanto, para poder usá-lo com os estudantes, os três bolsistas precisaram baixá-lo em seus aparelhos; em seguida, os levaram até a sala de aula.

Como pode ser visto na Figura 1, nesse aplicativo existem seis diferentes tipos de jogo: contrarrelógio, tempo infinito, aprendizado, duelo, tabela e exame. $O$ jogo escolhido para a atividade a ser realizada em sala de aula foi o Duelo. 
- Revista de Iniciação à Docência, v. 2, n. 2, 2017 Publicação: março, 2018 - ISSN 2525-4332

Figura 1 - Tela inicial do jogo Tabuada.

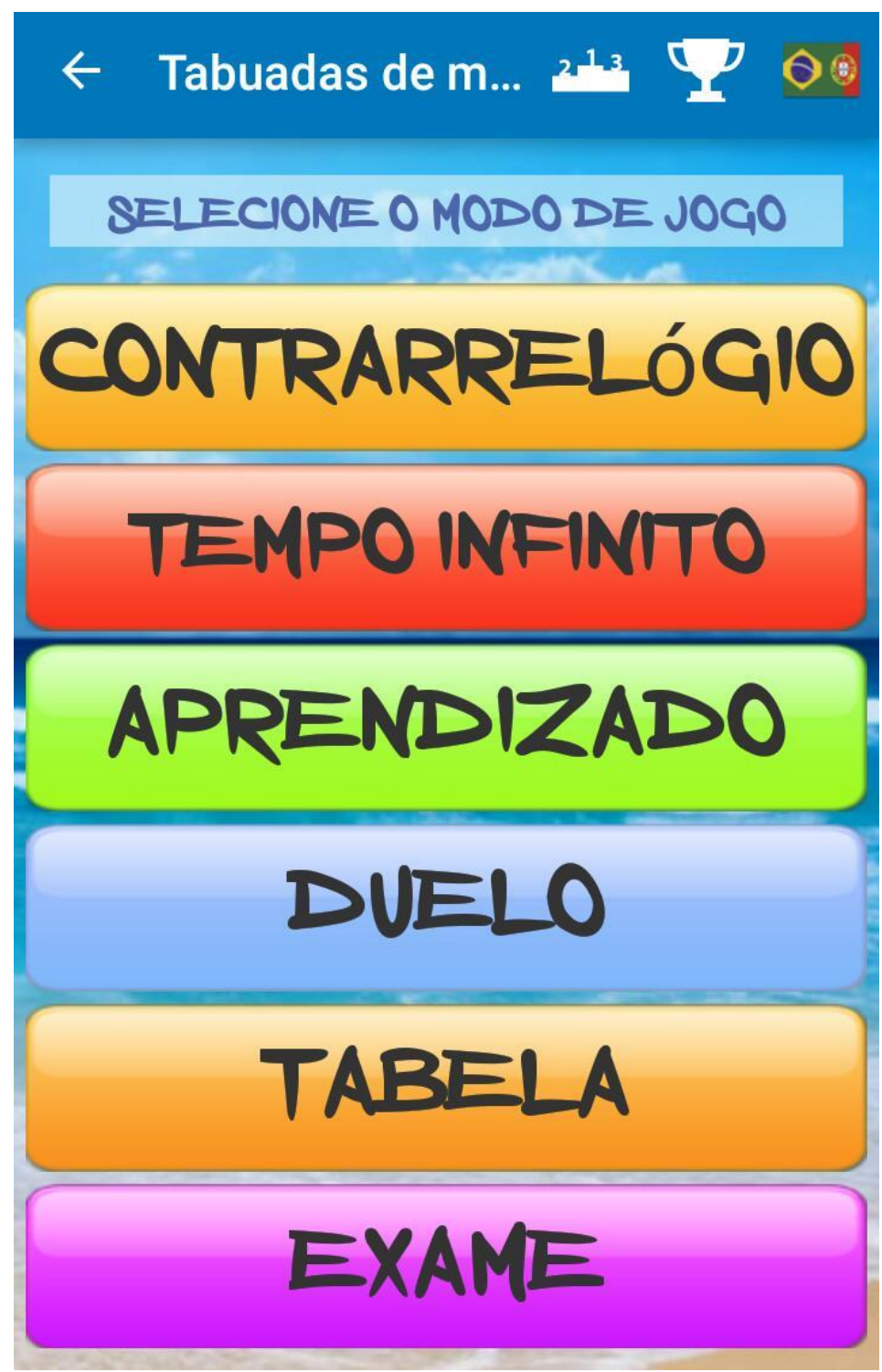

Fonte: Print screen do aplicativo Tabuada de Multiplicação. 
Figura 2 - 0 jogo duelo.

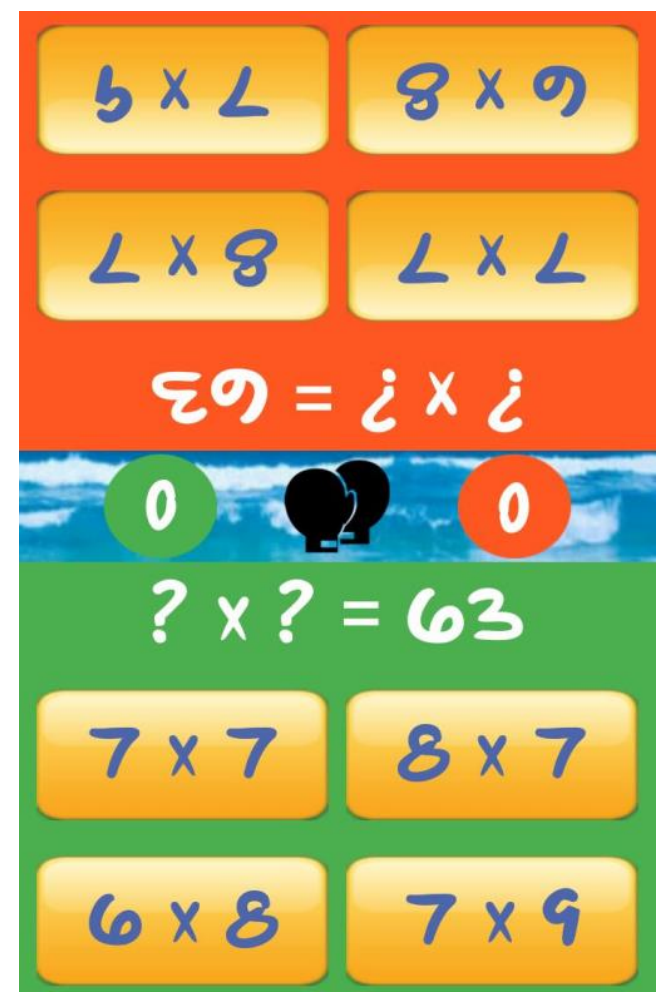

Fonte: Print screen do aplicativo Tabuada de Multiplicação.

Para jogar o Duelo, um aparelho celular foi colocado no centro de uma mesa e um aluno sentou de cada lado. Ao iniciar, aparecem duas contas iguais, cada uma virada para um jogador, e uma pergunta (cf. Figura 2). Os jogadores devem encontrar a resposta correta, entre quatro alternativas oferecidas pelo aplicativo, e clicar nela. Quem clicar primeiramente na resposta correta marca um ponto; ganha o jogo o competidor que primeiro chegar a 10 pontos, sendo então considerado o vencedor do duelo.

Para dar início à oficina, foi pedido para os alunos formarem um semi-círculo; em seguida, um dos bolsistas apresentou o jogo e explicou como seria realizado. Os bolsistas, que seriam os juízes dos jogos, organizaram também os sorteios dos duelos e as duplas sorteadas foram anotadas na lousa.

Uma vez definidos os duelos, iniciou-se o jogo. Para tanto, uma mesa onde seriam realizados os duelos foi colocada em frente ao semi-circulo. Enquanto dois alunos duelavam, o restante da sala deveria ficar estudando a tabuada, cada um sentado em seu lugar. 
- Revista de Iniciação à Docência, v. 2, n. 2, 2017 -

Publicação: março, 2018 - ISSN 2525-4332

Quando acabava um duelo, o próprio aplicativo mostrava qual dos dois jogadores tinha ganhado - e qual tinha perdido. $O$ vencedor iria automaticamente para a segunda fase.

Figura 3 - Duas alunas duelando.

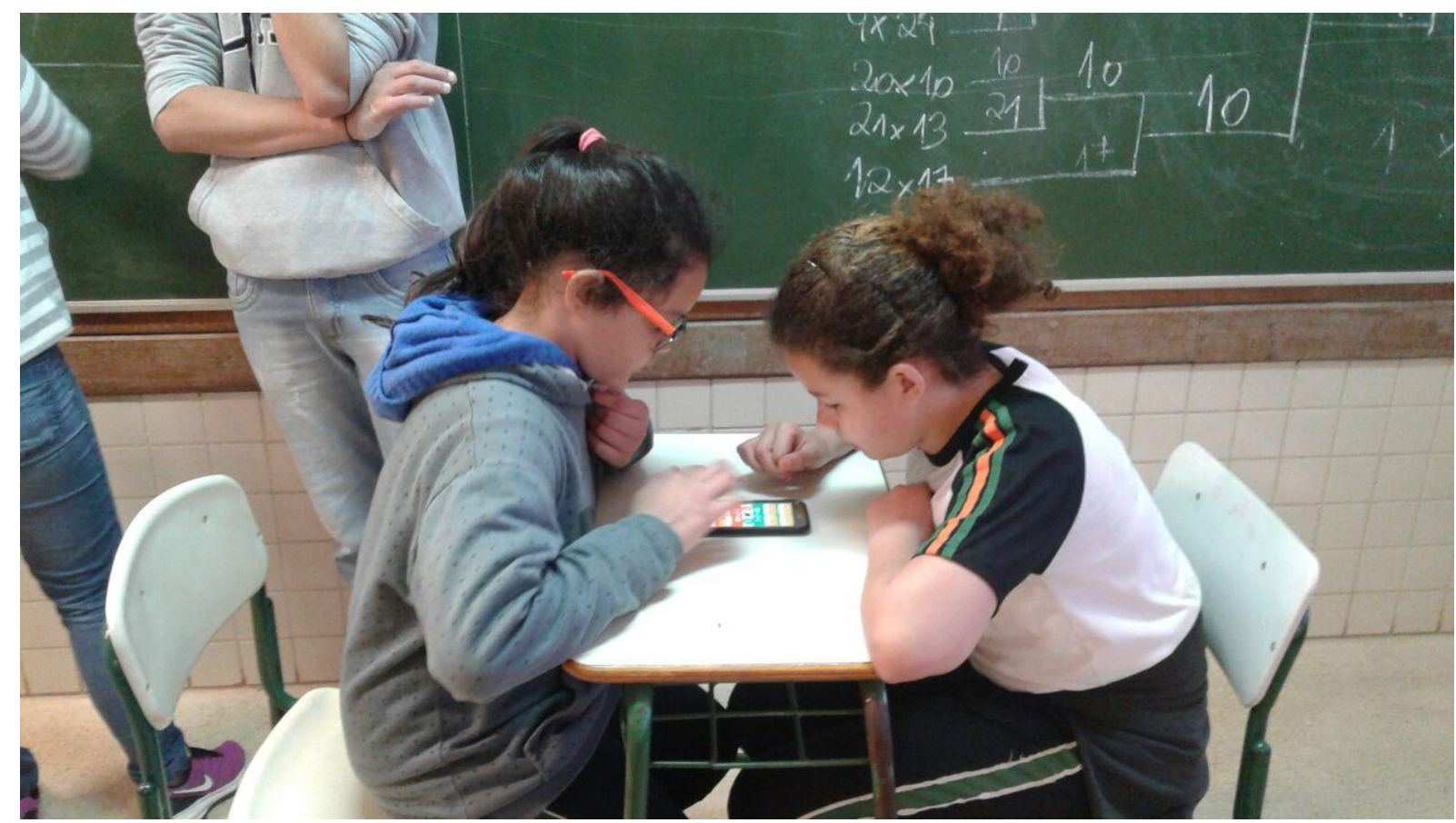

Fonte: Autora.

Quem perdia o duelo tinha mais uma chance de participar da "competição", pois jogava um novo duelo com outro aluno que também tinha perdido. Quem ganhasse esse novo duelo, também iria para segunda fase. Assim eram realizados os duelos: quem ganhava ia passando de fase, até chegar à semifinal.

As semifinais foram disputadas por quatro jogadores e, assim como na copa do mundo de futebol, os dois jogadores que perderam o duelo acabaram competindo pelo terceiro e quarto lugares, enquanto os dois que ganharam disputaram a final, na qual foram definidos o primeiro e o segundo lugares da competição.

Ao desenvolver essa atividade, ficou claro, para os bolsistas, que os alunos se interessaram bastante pelo jogo que foi proposto. Muitos perguntaram como fazer para baixar aquele aplicativo em seus celulares, para poderem jogar no intervalo e até mesmo em casa com seus familiares.

\section{O lúdico e o eletrônico em sala de aula}

Uma outra reflexão que os bolsistas fizeram, após a realização da prática descrita na seção anterior, foi a de que levar algo diferente para a sala de aula é deveras de grande 
relevância para o aprendizado dos alunos. Uma simples atividade fora do comum pode marcar a vida deles e motivá-los a buscar mais conhecimentos, estudar mais e até mesmo gostar de uma matéria da qual talvez antes não gostassem tanto. Por isso, é importante que o professor se mantenha sempre atualizado e que se utilize até da tecnologia, como auxílio em suas aulas.

Ora, no ensino superior o uso de programas e softwares como ferramentas de ensino está se tornando cada vez mais comum, mas até no contexto do ensino básico a tecnologia pode ser uma grande aliada dos professores, se utilizada oportunamente.

Como foi dito na introdução, tanto o Referencial Curricular Nacional para a Educação Infantil, quanto os Parâmetros Curriculares Nacionais de Matemática, incentivam o uso de jogos em sala de aula, além de pôr em relevo a importância do uso de novas tecnologias. Quando se lida com alunos de uma faixa etária entre a infância e a adolescência, os jogos ainda podem desenvolver papel de facilitadores da aprendizagem.

A atividade descrita neste trabalho constitui um válido exemplo disso, pois, conforme relatou a professora orientadora do PIBID no colégio onde ela foi desenvolvida, o desempenho geral dos discentes na prova seguinte foi bom. Mais importante do que isso, a atividade de fato despertou nos alunos um grande interesse pela tabuada de multiplicação e os motivou a estudá-la.

Há várias razões que podem explicar isso. Segundo Alves e Bianchin (2010), "um aspecto relevante nos jogos é o desafio que eles provocam no aluno, o que gera interesse e prazer" (p. 286). Atividades como aquela proposta pelos bolsistas do PIBID do curso de Matemática da UNESPAR/Apucarana ajudam a tornar agradável o ambiente da sala de aula, libertando os alunos das angústias que às vezes a pressão pelo resultado provoca ou do sentimento de opressão e de tédio que pode ser gerado por aulas pouco dinâmicas ou nas quais se exige que o aluno decore algo - como pode ser o caso, justamente, da tabuada de multiplicação.

Segundo Corrêa e Bento (2014), ademais, a introdução de jogos como recurso didático nas aulas de Matemática pode "diminuir os bloqueios apresentados por alguns alunos" (p. 7). É frequente o caso de discentes que têm medo de se expor em sala e responder às perguntas do professor, por timidez, insegurança, medo de errar e de ser reprovado pelo docente ou zombado pelos colegas, etc. No jogo tudo isso tende a desaparecer, os alunos se sentem à vontade para expressar-se livremente, sem medo de errar. Se acertar e ganhar, ótimo; senão, paciência. Bem diferente de quando se tenta responder a uma questão posta pelo professor ou de quando está se realizando uma prova.

O jogo, em suma, representa uma ótima ferramenta metodológica quando se lida com discentes de idade ainda muito jovem, incrementa a motivação desses estudantes e ajuda a remover obstáculos no processo de aprendizagem. 
E se o jogo, naquela faixa etária, ainda faz parte do cotidiano dos alunos, hoje em dia a tecnologia também representa algo presente em quase todos os aspectos da rotina dos estudantes. Por essa razão, tanto o jogar, quanto a utilização de recursos tecnológicos em sala de aula significa estabelecer comunicação com os discentes, utilizando-se da própria linguagem deles, o que evidentemente os aproxima do professor e contribui para que a comunicação flua de maneira eficaz e produtiva.

É evidente que jogos eletrônicos (ou computadorizados) e aplicativos de celular conjugam as duas coisas de um modo que pode ser certamente desfrutado para auxiliar no processo ensino-aprendizagem.

\begin{abstract}
Os games, embora com algumas semelhanças em sua elaboração com os jogos tradicionais, possibilitam para além da possibilidade de simulação, movimento, efeitos sonoros em sua utilização corriqueira, uma interação com uma nova linguagem oriunda do surgimento e do desenvolvimento das tecnologias digitais, da transformação do computador em aparato de comunicação e da convergência das mídias. Proporciona assim novas formas de sensibilidade, de sentir, pensar, de agir e interagir (MOITA, 2006, p. 29).
\end{abstract}

Ora, assim como para qualquer outra atividade em sala de aula, "para que os jogos e brincadeiras sejam considerados ferramentas eficazes para o ensino-aprendizagem é preciso uma planificação organizada, contendo objetivos e metas" (BARANITA, 2012, p. 53). Diferentemente, o jogo passa a ser uma atividade sem fundamento, se desenvolvida apenas para preencher o tempo de aula. O uso de jogos para computador, eletrônicos ou para telefone celular como suporte pedagógico no aprendizado de conteúdos específicos, ao invéz,

deve ser compreendido como uma metodologia importante no processo de ensino aprendizagem, pois com o lúdico a criança aprende tão bem ou até melhor do que em qualquer atividade tradicional limitada a livros e cadernos. $O$ fato de estar em um momento descontraído não representa um momento de lazer apenas, e sim uma forma alternativa de ensinar e aprender (FERNANDES; JUNIOR, 2012, p. 9-10).

Por isso, os docentes precisam conhecer o jogo que irão propor e utilizar em sala. É preciso planejar seu uso e pensar sobre o tipo de aproveitamento que desejam obter por meio de tal atividade. "Ao professor, cabe analisar e avaliar a potencialidade educativa dos diferentes jogos, permitindo assim um trabalho pedagógico mais envolvente" (ALVES; BIANCHIN, 2010, p. 286).

Foi esse o caso da prática realizada pelos bolsistas do PIBID e descrita no presente trabalho. $O$ jogo proposto era conhecido e seu uso em sala de aula foi planejado em uma reunião, na qual foram avaliadas as potencialidades e a utilidade do aplicativo, tendo em vista a finalidade de fazer com que os alunos estudassem e assimilassem a tabuada de multiplicação e o fizessem mostrando interesse e vontade de aprender - e que, possivelmente, obtivéssem bons resultados na prova da semana seguinte. 


\section{Conclusão}

Apesar de ser relativamente simples, a atividade descrita neste trabalho - realizada em uma tarde de agosto em um colégio do interior parananense - traz à tona a importância do uso da tecnologia em sala de aula e da necessitade de um ensino mais em sintonia com os tempos atuais. Pois como bem diz, com uma célebre frase, o informático estadunidense Alan Kay, "a tecnologia só é tecnologia para quem nasceu antes dela ter sido inventada" (DAHER, 2015, p. 125). Conforme foi dito anteriormente, os alunos de hoje já nascem nessa era tecnológica - são 'nativos digitais' - e não podem vivê-la apenas fora da escola. Para eles, é normal ter contato com os produtos da ciência e da engenharia em todas as situações da sua vida. Por que na escola, que representa um momento tão importante no cotidiano e na vida deles, deveria ser diferente?

Para obviar a isso, os professores devem atualizar-se constantemente, buscar formas de trazer a tecnologia para dentro da sala, utilizar softwares e aplicativos que possam auxiliá-los em suas aulas. Mas eles não podem ser deixados a sós nessa empreitada. As instituições devem suportá-los e incentivá-los - o que não parece ser o caso, particularmente na fase em que o país se encontra atualmente.

A simples oficina realizada no Colégio Estadual Antonio dos Três Reis de Oliveira, em Apucarana/PR, mostrou que os alunos se dedicam mais para aprender um determinado conteúdo quando este é ensinado de forma dinâmica e divertida. Ainda mais em se tratando de turmas do $6^{\circ}$ ano e, portanto, de discentes muito jovens, de idade média de aproximadamente $11-12$ anos.

Quando se sai da rotina de apenas copiar a matéria e resolver uma conta no caderno, para jogar um jogo no período da aula, sobre aquele mesmo conteúdo, o interesse da turma aumenta e o desempenho geral melhora. Isso certamente não surpreende, pois, conforme relata Isabel Baranita:

\footnotetext{
foram muitos os teóricos da educação que ao longo dos tempos se debruçaram sobre o papel dos jogos no contexto escolar. Aos poucos o jogo foi ganhando espaço no meio escolar e nos dias de hoje, os jogos são considerados por muitos educadores (...) um meio excelente para formar a criança, sendo indispensáveis ao processo ensino-aprendizagem (BARANITA, 2012, p. 49).
}

Sendo assim, por que na formação de educadores/professores não existem disciplinas centradas no lúdico? Frente a essa lacuna, Baranita justamente se pergunta: "como podemos esperar que estes profissionais desenvolvam com segurança uma prática que priorize jogos e brincadeiras no espaço escolar?" (BARANITA, 2012, p. 51). A mesma autora acrescenta: 
- Revista de Iniciação à Docência, v. 2, n. 2, 2017 -

Publicação: março, 2018 - ISSN 2525-4332

Podemos concluir que a questão do carater lúdico na formação de docentes é de extrema importância; daí ser urgente inserir nos currículos de formação educacional cadeiras que foquem fundamentos metodológicos e teóricos sobre o jogo e que demonstrem a importância do lúdico na prática pedagógica destes futuros profissionais (BARANITA, 2012, p. 52).

É comum, nos cursos de licenciatura no Brasil (em Matemática, mas não somente) a presença de disciplinas focadas no uso das novas tecnologias em sala de aula. Por que não ter inclusive disciplinas dedicadas ao lúdico no processo ensino-aprendizagem, assim como a autora que acabou de ser citada almeja acontecer em Portugal?

\section{Referências}

ALVES, L.; BIANCHIN, M. A. O jogo como recurso de aprendizagem. Revista Psicopedagia (Online), s.l., v. 27, n. 83, p. 282-287, 2010.

BARANITA, I. A importância do jogo no desenvolvimento da criança. Dissertação de Mestrado, Escola Superior de Educação Almeida Garrett, Lisboa, 2012.

CORRÊA, L. S.; BENTO, R. M. de L. A importância do lúdico para a aprendizagem na educação infantil. Jiparaná/RO, 2014. Disponível em: http://unijipa.edu.br/media/files/54/54_218.pdf. Acesso em: 20/11/2017.

DAHER, E. A culpa é da informática. Clube de Autores, 2015.

FERNANDES, R. J. G.; JUNIOR, G. dos S. The sims: jogo computacional como uma ferramenta pedagógica na construção do conhecimento matemático. Revista Eletrônica TECCEN, Vassouras, v. 5, n. 1, p. 21-36, 2012.

JACOBSEN, D. R.; SPEROTTO, R. I. Jogos eletrônicos: um aprender lúdico e virtual para o Ensino da Matemática. Canoas/RS, 2013. VI CONGRESSO INTERNACIONAL DE ENSINO DE MATEMÁTICA. Anais... Canoas/RS: ULBRA, 2013. Disponível em:

http://www.conferencias.ulbra.br/index.php/ciem/vi/paper/viewFile/787/622. Acesso em: 20/11/2017.

MOITA, F. M. G. da S. C. Games: contexto cultural e currículo juvenil. Tese de Doutorado. Universidade Federal da Paraíba, João Pessoa, 2006.

MOURA, M. O. O jogo e a construção do conhecimento matemático. In: Ideias. O jogo e a construção do conhecimento na pré-escola. São Paulo, FDE, n. 10, 1991, p. 45-53

PRENSKY, M. O papel da tecnologia no ensino e na sala de aula. Conjectura, Caxias do Sul, v. 15, n. 2, p. 201-204, 2010. 